\title{
PENGARUH CITRA MEREK TERHADAP LOYALITAS NASABAH PADA PT.BRI UNIT BUMI NYIUR
}

\author{
Dewi Indra Lestiani \\ Syamsul Bahri \\ Elimawaty Rombe \\ Jurusan Manajemen, Fakultas Ekonomi, Universitas Tadulako \\ Email: dewiindral91@yahoo.com
}

\begin{abstract}
This study aims to analyze the influence of: (1) brand image, consisting of corporate image, customer image, and product image on customer loyalty at PT. BRI Unit Bumi Nyiur Palu. (2) corporate image on customer loyalty at PT. BRI Unit Bumi Nyiur of Palu. (3) customer image on customer loyalty at PT. BRI Unit Bumi Nyiur of Palu. (4) product image on customer loyalty at PT. BRI Unit Bumi Nyiur of Palu. Type of study is causal descriptive. Population includes customers at PT. BRI Unit Bumi Nyiur of Palu. Sampling technique is purposive sampling, with 100 respondents as samples. Method of analysis is multiple regression analysis. The results show that (1) brand image consisting of corporate image, customer image, and product image simultaneously have significant influence on customer loyalty at PT. BRI Unit Bumi Nyiur of Palu (2) Corporate image has a significant influence on customer loyalty at PT. BRI Unit Bumi Nyiur of Palu, (3) customer image has a significant influence on customer loyalty at PT. BRI Unit Bumi Nyiur of Palu, (4) product image significantly influences customer loyalty at PT. BRI Unit Bumi Nyiur of Palu.
\end{abstract}

Keywords: brand image, customer loyalty.

\section{ABSTRAK}

Penelitian ini bertujuan untuk menganalisa: (1) pengaruh citra merek yang terdiri dari citra perusahaan, citra konsumen, dan citra produk terhadap loyalitas nasabah pada PT. BRI Unit Bumi Nyiur Palu. (2) pengaruh citra perusahaan terhadap loyalitas nasabah pada PT. BRI Unit Bumi Nyiur Palu. (3) pengaruh citra konsumen terhadap loyalitas nasabah pada PT. BRI Unit Bumi Nyiur Palu. (4) pengaruh citra produk terhadap loyalitas nasabah pada PT. BRI Unit Bumi Nyiur Palu. Jenis penelitian yang digunakan adalah Deskriptif Kausal. Populasi dalam penelitian ini adalah masyarakat Kota Palu yang merupakan nasabah pada PT. BRI Unit Bumi Nyiur Palu. Teknik penarikan sampel menggunakan purposive sampling, dengan jumlah sampel sebanyak 100 responden. Metode analisis menggunakan analisis regresi berganda. Hasil penelitian menunjukkan bahwa (1) Citra merek yang terdiri dari citra perusahaan, citra konsumen, dan citra produk, berpengaruh signifikan terhadap loyalitas nasabah pada PT. BRI Unit Bumi Nyiur Palu (2) Citra perusahaan berpengaruh signifikan terhadap loyalitas nasabah pada PT. BRI Unit Bumi Nyiur Palu, (3) Citra kosumen berpengaruh signifikan terhadap loyalitas nasabah pada PT. BRI Unit Bumi Nyiur Palu, (4) Citra produk berpengaruh signifikan terhadap loyalitas nasabah pada PT. BRI Unit Bumi Nyiur Palu.

Kata Kunci: Citra Merek, Loyalitas Konsumen.

\section{PENDAHULUAN}

PT. Bank Rakyat Indonesia khususnya Unit Bumi Nyiur Kantor Wilayah Kota Palu adalah salah satu unit nomor satu terbesar di Kota Palu yang berlokasi strategis ditengah kota sehingga aksesnya cukup mudah bagi masyarakat, hal ini terbukti dengan selalu ramainya para konsumen yang berdatangan di unit tersebut pada hari dan jam kerja. Hal ini didukung dengan hasil obervasi sementara peneliti yang juga menemukan peningkatan yang baik terhadap nasabah dalam menggunakan produk-produk dari PT. Bank Rakyat Indonesia khususnya Unit Bumi Nyiur Kantor Wilayah Kota Palu.

\section{Tabel 1}


Lestiani, D.I.

Jumlah nasabah dan jumlah rekening pada PT. BRI Unit Bumi Nyiur

\begin{tabular}{|l|l|l|l|}
\hline No & Tahun & Jumlah Nasabah & Jumlah Rekening nasabah \\
\hline 1. & 2014 & 11.106 & 11.616 \\
\hline 2. & 2015 & 12.349 & 13.222 \\
\hline 3. & 2016 & 13.298 & 14.364 \\
\hline 4. & Total & 36.753 & 39.202 \\
\hline
\end{tabular}

Berdasarkan Tabel di atas, yakni hasil analisis mengenai peningkatan jumlah nasabah dan jumlah rekening pada PT. BRI Unit Bumi Nyiur dalam tiga tahun terakhir yakni dari tahun 2014 sampai dengan 2016 adalah jumlah nasabah sebanyak 36.753 dan jumlah rekening adalah 39.202. Berdasarkan masalah di atas, maka tujuan penelitian ini adalah sebagai berikut:

1. Untuk mengetahui dan menganalisis pengaruh citra merek yang terdiri dari citra perusahaan, citra konsumen, dan citra produk terhadap loyalitas nasabah pada PT. Bank Rakyat Indonesia Tbk Unit Bumi Nyiur Kantor Wilayah Kota Palu.

2. Untuk mengetahui dan menganalisis pengaruh citra perusahaan terhadap loyalitas nasabah pada PT. Bank Rakyat Indonesia Tbk Unit Bumi Nyiur Kantor Wilayah Kota Palu.

3. Untuk mengetahui dan menganalisis pengaruh citra konsumen terhadap loyalitas nasabah pada PT. Bank Rakyat Indonesia Tbk Unit Bumi Nyiur Kantor Wilayah Kota Palu.

4. Untuk mengetahui dan menganalisis pengaruh citra produk terhadap loyalitas nasabah pada PT. Bank Rakyat Indonesia Tbk Unit Bumi Nyiur Kantor Wilayah Kota Palu.

\section{KAJIAN LITERATURE}

\section{Pengertian Pemasaran dan Manajemen Pemasaran}

Pemasaran mengidentifikasi dan memenuhi kebutuhan manusia dan sosial. Kotler dan Keller (2009:5) pemasaran secara sosial adalah sebuah proses kemasyarakatan di mana individu dan kelompok memperoleh apa yang mereka butuhkan dan inginkan dengan menciptakan, menawarkan, dan secara bebas mempertukarkan produk dan jasa yang bernilai dengan orang lain. Tujuan pemasaran adalah mengetahui dan memahami pelanggan dengan baik sehingga produk atau jasa bias sesuai dengan kebutuhannya sehingga terjual sendiri (Kotler dan Keller, 2009:6).Pemasaran adalah proses mengidentifikasi, menciptakan dan mengkomunikasikan nilai, serta memelihara hubungan yang memuaskan pelanggan untuk memaksimalkan keuntungan perusahaan (Husein, 2013: 4).

\section{Pengertian Citra Merek}

Citra merek adalah persepsi dan kepercayaan oleh konsumen sebagai gambaran dari asosiasi yang terdapat dalam memori konsumen. Menurut Kotler dan Keller (2012:274), pengertian citra adalah cara masyarakat menganggap merek secara aktual. Agar citra dapat tertanam dalam pikiran konsumen, pemasar harus memperlihatkan identitas merek melalui saran komunikasi dan kontak merek yang tersedia. Citra terhadap merek berhubungan dengan sikap yang berupa keyakinan dan preferensi terhadap suatu merek (Sangadji dan Sopiah, 2013).

Menurut Ferrinadewi (2008:165) Citra merek adalah persepsi tentang merek yang merupakan refleksi memori konsumen akan asosiasinya pada merek tersebut. Roslina (2010:334) Citra merek merupakan petunjuk yang akan digunakan oleh konsumen untuk mengevaluasi produk ketika konsumen tidak memiliki pengetahuan yang cukup tentang suatu produk. Tjiptono (2011:112), brand image atau brand description yakni deskrispi tentang asosiasi dan keyakinan konsumen terhadap merek tertentu. Sejumlah teknik kuantitatif dan kualitatif telah dikembangkan untuk membantu mengungkap presepsi dan asosiasi konsumen terhadap sebuah merek tertentu, diantaranya multidimensional scaling, projection techniques, dan sebagainya. 


\section{Komponen Citra Merek}

Tjiptono (2008:22) Komponen citra merek (brand image) terdiri atas tiga bagian yaitu :

1. Citra perusahaan (corporate image) yaitu sekumpulan asosiasi yang dipersepsikan konsumen terhadap perusahaan yang membuat suatu barang/jasa. Meliputi: nama baik perusahaan, popularitas perusahaan dan perusahaan terpercaya

2. Citra Konsumen (Customer image) yaitu sekumpulan asosiasi yang dipersepsikan oleh konsumen terhadap pemakai yang menggunakan suatu barang/jasa. Meliputi:gaya hidup atau kepribadian dan kelas sosialnya

3. Citra produk (product image) yaitu sekumpulan asosiasi yang dipersepsikan konsumen terhadap suatu barang/jasa. Meliputi: atribut dari produk, manfaat bagi konsumen serta jaminan.

\section{Faktor-Faktor Yang Membentuk Citra Merek}

Schiffman dan Kanuk (2013:31) menyebutkan faktor-faktor pembentuk citra merek adalah sebagai berikut:

1. Dapat dipercaya atau diandalkan, berkaitan dengan pendapat atau kesepakatan yang dibentuk oleh masyarakat tentang suatu produk yang dikonsumsi.

2. Kegunaan atau manfaat, yang terkait dengan fungsi dari suatu produk barang yang bisa dimanfaatkan oleh konsumen.

3. Pelayanan yang berkaitan dengan tugas produsen dalam melayani konsumennya.

4. Resiko, berkaitan dengan besar kecilnya akibat atau untung dan rugi yang mungkin dialami oleh konsumen.

5. Harga, dalam hal ini berkaitan dengan tinggi rendahnya atau banyak sedikitnya jumlah uang yang dikeluarkan konsumen untuk mempengaruhi suatu produk, juga dapat mempengaruhi citra jangka panjang.

\section{Loyalitas nasabah}

Menurut Anthony (2012:26) Loyalitas adalah pilihan yang dilakukan konsumen untuk membeli merek tertentu dibanding merek yang lain dalam kategori produk. Persepsi merupakan salah satu aspek tersebut dan sebelum persepsi konsumen terbentuk suatu objek, dalam hal ini kwalitas, harga, dan suasana toko merupakan faktor yang memotifasi konsumen dalam suatu produk. Konsumen mempunyai rasa suka dan tidak suka setelah mereka membeli produk dan kemudian persepsi terbentuk dan aan menentukan perilaku terhadap merek produk tersebut.

Menurut Griffin (2005:5) berpendapat bahwa seorang pelangan diatakan setia atau loyal apabila pelanggan tersebut menunjukan perilaku pembelian secara teratur atau terdapat suatu kondisi dimana mewajibkan pelanggan membeli paling sedikit dua kali dalam selang waktu tertentu. Upaya memberikan kepuasan pelanggan, sedangkan konsep loyalitas pelanggan lebih berkaitan dengan perilaku pelanggan dari pada sikap dari pelanggan.Konsumen dengan loyalitas tinggi akan memberitahukan keunggulan dan walitas layanan tersebut pada orang lain bahkan sering memberikan saran untuk mrnggunakan layanan jasa yang diberikan kepada konsumen.

\section{Pengukuran Loyalitas}

Griffin (2005: 31) mengatakan bahwa loyalitas pelanggan tampaknya merupakan ukuran yang lebih dapat diandalkan untuk memprediksi pertumbuhan penjualan dan keuangan.Berbeda dari kepuasan, yang merupakan sikap, loyalitas dapat didefinisikan berdasarkan perilaku membeli. Pelanggan yang loyal adalah orang yang:

1. Melakukan pembelian berulang secara teratur. Pelanggan yang loyal adalah mereka yang melakukan pembelian barang ataupun jasa secara teratur bahkan mereka akan tetap membeli meskipun harganya mengalami kenaikan. 
2. Membeli antar lini produk dan jasa. Pelanggan yang loyal bukan hanya membeli satu jenis produk atau jasa saja dari sebuah perusahaan, melainkan mereka juga membeli produk ataupun jasa tambahan yang disediakan oleh perusahaan tersebut.

3. Merekomendasikan kepada orang lain. Pelanggan yang loyal selalu ingin mereferensikan suatu produk atau jasa yang digunakannya kepada orang lain, baik kepada teman maupun saudara. Mereka selalu berusaha mempengaruhi orang lain untuk menggunakan produk atau jasa yang sama dengan selalu menceritakan kelebihan produk atau jasa yang dia gunakan sampai orang tersebut mencoba menggunakannya.

4. Menunjukkan kekebalan terhadap tarikan dari pesaing. Para pelanggan yang loyal selalu menolak apabila ditawari produk atau jasa dari perusahaan lain (pesaing). Mereka sudah memiliki kecintaan tersendiri terhadap produk atau jasa yang telah digunakan.

\section{Kerangka Pemikiran}

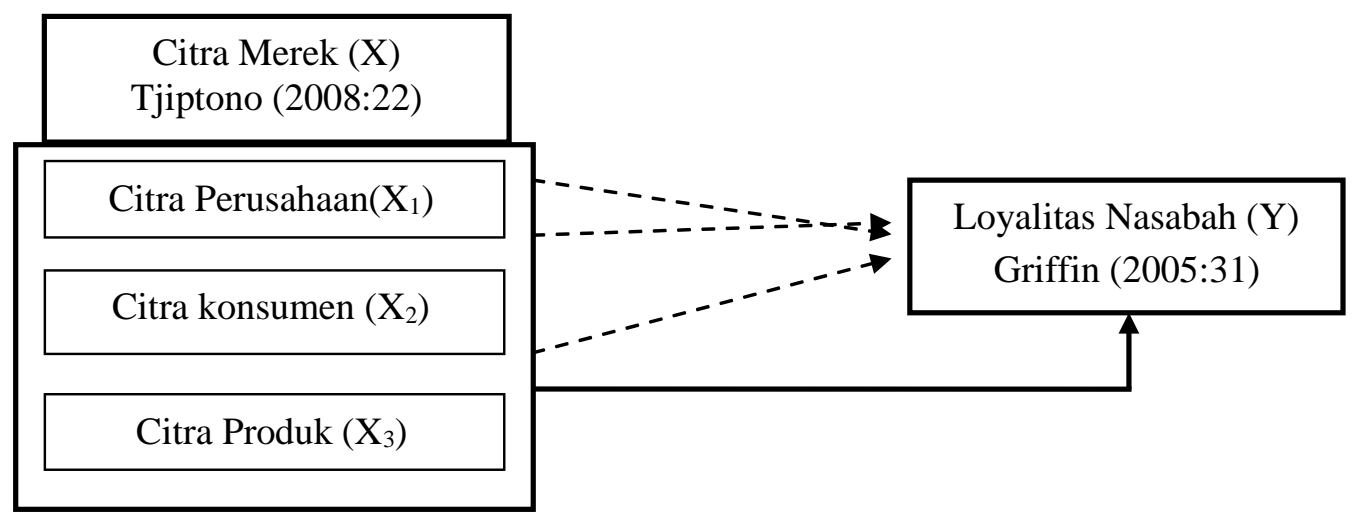

Gambar 1

Kerangka Pemikiran

Hipotesis disusun berdasarkan teori dan kerangka berpikir yang sudah diuraikan sebelumnya, maka dari teori dan kerangka berpikir diatas dapat disusun beberapa hipotesis sebagai berikut:

1. Citra merek yang terdiri dari citra perusahaan (X1), citra konsumen (X2), dan citra produk (X3) berpengaruh signifikan terhadap loyalitas nasabah pada PT. Bank Rakyat Indonesia Tbk Unit Bumi Nyiur Kantor Wilayah Kota Palu.

2. Variabel citra perusahaan (X1) berpengaruh signifikan terhadap loyalitas nasabah pada PT. Bank Rakyat Indonesia Tbk Unit Bumi Nyiur Kantor Wilayah Kota Palu.

3. Variabel citra kosumen (X2) berpengaruh signifikan terhadap loyalitas nasabah pada PT. Bank Rakyat Indonesia Tbk Unit Bumi Nyiur Kantor Wilayah Kota Palu.

4. Variabel citra produk (X3) berpengaruh signifikan terhadap loyalitas nasabah pada PT. Bank Rakyat Indonesia Tbk Unit Bumi Nyiur Kantor Wilayah Kota Palu.

\section{METODE PENELITIAN}

Jenis penelitian yang digunakan dalam penelitian ini adalah penelitian kausalitas. penelitian kausalitas adalah penelitian yang dilakukan untuk menggambarkan skema hubungan dan pengaruh dua variabel atau lebih, serta bagaimana satu variabel mempengaruhi variabel lainnya Jenis data yang digunakan dalam penelitian ini adalah data primer. Penelitian ini dilakukan di Kota Palu, pada PT. Bank Rakyat Indonesia, Tbk Unit Bumi Nyiur Kantor Wilayah Kota Palu yang berlokasi di Jl. Setia Budi No.60. Sedangkan waktu penelitian direncanakan pada bulan Oktober sampai November. 
Populasi dalam penelitian ini adalah masyarakat Kota Palu yang merupakan nasabah pada PT. Bank Rakyat Indonesia Tbk Unit Bumi Nyiur Kantor Wilayah Kota Palu. Populasinya merujuk pada data jumlah nasabah pada tahun 2016 yaitu 13.298 orang. Berdasarkan jumlah populasi tersebut untuk mengetahui besaran sampel dapat menggunakan rumus Slovin (Husein, 2010:146) yaitu:

$\mathrm{n}=\mathrm{N} /(1+\mathrm{N} .(\mathrm{e}) 2)$

$\mathrm{n}=13.298 /(1+13.298 .(0,1) 2)$

$\mathrm{n}=13.298 /(1+13.298 .(0.01))$

$\mathrm{n}=13.298 /(1+132,98)$

$\mathrm{n}=13.298 / 133,98$

$\mathrm{n}=99,2$ sehingga dibulatkan menjadi 100 orang.

Penelitian ini menggunakan aplikasi software SPSS (Statistical Program for Social Scane) versi 16.0 yang dipakai untuk menganalisis pengaruh secara simultan dan pengaruh secara parsial variabel Independen terhadap dependen. Teknik analisis data yang dipergunakan dalam penelitian ini analisis deskriptif dan Analisis Regresi Berganda. Mengukur dan menganalisis besarnya hubungan citra merek terhadap loyalitas nasabah, menggunakan alat analisis statistic parametric regresi linear berganda (Multiple Regression Analisis). Menurut Sugiyono (2014:277) bahwa model umum bentuk persamaan alat analisis statistic parametric regresi linear berganda dapat digambarkan sebagai berikut persamaan struktural dalam model sebagai berikut:

$\mathbf{Y}=\mathbf{a}+\mathbf{b}_{1} \mathbf{X}_{1}+\mathbf{b}_{2} \mathbf{X}_{2}+\mathbf{b}_{3} \mathbf{X}_{3}+\mathbf{e}$

Dimana:

$\mathrm{Y}=$ Loyalitas Nasabah

$\mathrm{X}_{1}=$ Citra Perusahaan

$\mathrm{X}_{2}=$ Citra Konsumen

$\mathrm{X}_{3}=$ Citra Produk

$\mathrm{A}=$ Konstanta

$\mathrm{b}_{1-} \mathrm{b}_{2}=$ Koefisien Regresi

4. HASIL DAN PEMBAHASAN

HASIL PENELITIAN

Analisis Deskriptif

Tabel 2

Rekapitulasi Nilai Mean Jawaban responden

\begin{tabular}{|c|c|c|c|c|}
\hline Variabel & $\begin{array}{c}\text { Nilai Mean } \\
\text { Tertinggi }\end{array}$ & $\begin{array}{c}\text { Nilai Mean } \\
\text { Terendah }\end{array}$ & $\begin{array}{c}\text { Rata-rata } \\
\text { Nilai Mean }\end{array}$ & Ket \\
\hline $\begin{array}{c}\text { Citra Perusahaan } \\
(\mathrm{X} 1)\end{array}$ & $\begin{array}{c}4,21 \\
\text { Popularitas Perusahaan } \\
(\mathrm{X} 1.2)\end{array}$ & $\begin{array}{c}4,06 \\
\text { Perusahaan Terpercaya } \\
(\mathrm{X} 1.3)\end{array}$ & 4,13 & $\begin{array}{c}\text { Sangat } \\
\text { Baik }\end{array}$ \\
\hline $\begin{array}{c}\text { Citra Konsumen } \\
(\mathrm{X} 2)\end{array}$ & $\begin{array}{c}4,43 \\
\text { Gaya Hidup (X2.1) }\end{array}$ & $\begin{array}{c}4,10 \\
\text { Status sosial (X2.2) }\end{array}$ & 4,26 & $\begin{array}{c}\text { Sangat } \\
\text { Baik }\end{array}$ \\
\hline $\begin{array}{c}\text { Citra Produk } \\
(\mathrm{X} 3)\end{array}$ & $\begin{array}{c}4,39 \\
\text { Jaminan bagi konsumen } \\
(\mathrm{X} 3.3)\end{array}$ & $\begin{array}{c}\text { Manfaat bagi konsumen } \\
(\mathrm{X} 3.2)\end{array}$ & 4,13 & $\begin{array}{c}\text { Sangat } \\
\text { Baik }\end{array}$ \\
\hline $\begin{array}{c}4,43 \\
\text { Loyalitas }\end{array}$ & $\begin{array}{c}4,14 \\
\text { Merekomendasikan ke } \\
\text { orang lain (Y3) }\end{array}$ & $\begin{array}{c}\text { Melakukan pembelian } \\
\text { ulang (Y1) }\end{array}$ & 4,24 & $\begin{array}{c}\text { Sangat } \\
\text { Baik }\end{array}$ \\
\hline
\end{tabular}


Berdasarkan Tabel diatas dapat disimpulkan:

1. Pada variabel citra perusahaan (X1) nilai mean tertinggi jawaban responden adalah indikator popularitas perusahaan (X1.2) dan nilai mean terendah adalah indikator perusahaan terpercaya (X1.3), dan diperoleh nilai rata-rata mean sebesar 4,13 yang berarti jawaban responden terhadap variabel citra perusahaan di tanggapi sangat baik.

2. Pada variabel citra konsumen (X2) nilai mean tertinggi jawaban responden adalah indikator gaya hidup (X2.1) dan nilai mean terendah adalah indikator status sosial (X2.2), dan diperoleh nilai ratarata mean sebesar 4,26 yang berarti jawaban responden terhadap variabel citra konsumen di tanggapi sangat baik.

3. Pada variabel citra produkn (X3) nilai mean tertinggi jawaban responden adalah indikator jaminan bagi konsumen (X3.3) dan nilai mean terendah adalah indikator manfaat bagi konsumen (X3.2), dan diperoleh nilai rata-rata mean sebesar 4,13 yang berarti jawaban responden terhadap variabel citra produk di tanggapi sangat baik.

4. Pada variabel loyalitas nasabah (Y) nilai mean tertinggi jawaban responden adalah indikator merekomendasikan ke orang lain (Y3) dan nilai mean terendah adalah indikator melakukan pembelian ulang (Y1), dan diperoleh nilai rata-rata mean sebesar 4,24 yang berarti jawaban responden terhadap variabel loyalitas nasabah di tanggapi sangat baik.

\section{Analisis Regresi Berganda}

Tabel 3

Ringkasan Hasil Analisis Regresi Linear Berganda

\begin{tabular}{|c|c|c|c|c|c|}
\hline \multicolumn{6}{|c|}{ Dependen Variabel Y = Loyalitas Nasabah } \\
\hline \multirow[t]{2}{*}{ Variabel Independen } & \multicolumn{2}{|c|}{$\begin{array}{c}\text { Unstandardized } \\
\text { Coefficients }\end{array}$} & \multirow{2}{*}{$\begin{array}{c}\begin{array}{c}\text { Standardized } \\
\text { Coefficients }\end{array} \\
\text { Beta }\end{array}$} & \multirow[t]{2}{*}{$\mathbf{t}$} & \multirow[t]{2}{*}{ Sig } \\
\hline & B & $\begin{array}{l}\text { Standar } \\
\text { Error }\end{array}$ & & & \\
\hline $\mathrm{C}=$ Constanta & .186 & .172 & & 1.080 & .283 \\
\hline Citra perusahaan $\left(\mathrm{X}_{1}\right)$ & .596 & .039 & .660 & 15.268 & .000 \\
\hline Citra konsumen $\left(\mathrm{X}_{2}\right)$ & .473 & .037 & 496 & 12.739 & .000 \\
\hline Citra produk $\left(\mathrm{X}_{3}\right)$ & .105 & .039 & .108 & 2.664 & .009 \\
\hline Multiple $\mathrm{R}=.943$ & & & $=.000$ & & \\
\hline $\mathrm{R}$ Square $\left(\mathrm{R}^{2}\right)=.888$ & & $\mathrm{~F}$ & $=254.801$ & & \\
\hline
\end{tabular}

Hasil tersebut apabila ditulis dalam bentuk persamaan regresinya adalah sebagai berikut:

$$
\mathrm{Y}=\mathbf{0 . 1 8 6}+\mathbf{0 , 5 9 6 \times 1}+\mathbf{0 , 4 7 3 X 2}+\mathbf{0 , 1 0 5 X 3}
$$

\section{PEMBAHASAN}

\section{Pengujian Hipotesis Pertama (Uji F)}

Berdasarkan Tabel 3, diperoleh angka signifikansi $F$ sebesar 0,000. Angka 0,000 $<0,05$ oleh karena itu, Ho ditolak dan Ha diterima. Artinya adanya pengaruh signifikan variabel citra merek yang terdiri dari citra perusahaan (X1), citra konsumen (X2), dan citra produk (X3) terhadap loyalitas nasabah pada PT. Bank Rakyat Indonesia Tbk Unit Bumi Nyiur Kantor Wilayah Kota Palu.

\section{Pengujian Hipotesis (Hasil Uji t)}

Variabel Citra Perusahaan $\left(\mathbf{X}_{1}\right)$

Berdasarkan Tabel 3, hasil pengujian dengan SPSS diperoleh angka signifikansi sebesar 0,000. Angka $0,000<0,05$ oleh karena itu, hipotesis diterima. Hal ini berarti variabel $\mathrm{X}_{1}$ (citra perusahaan) berpengaruh terhadap variabel Y (loyalitas nasabah). 


\section{Variabel Citra Konsumen $\left(\mathbf{X}_{2}\right)$}

Berdasarkan Tabel 3, hasil pengujian dengan SPSS angka signifikansi sebesar 0,000. Angka 0,000 $<0,05$ oleh karena itu, hipotesis diterima. Hal ini berarti variabel $\mathrm{X}_{2}$ (citra konsumen) berpengaruh terhadap variabel Y (loyalitas nasabah).

\section{Variabel Citra Produk $\left(\mathbf{X}_{3}\right)$}

Berdasarkan Tabel 3, hasil pengujian dengan SPSS angka signifikansi sebesar 0,009. Angka 0,009 $<0,05$ oleh karena itu, hipotesis diterima. Hal ini berarti variabel $\mathrm{X}_{3}$ (citra produk) berpengaruh terhadap variabel Y (loyalitas nasabah).

\section{Koefisien Determinasi $\left(\mathbf{R}^{2}\right)$}

Koefisien determinasi $\left(\mathrm{R}^{2}\right)$ pada intinya mengukur seberapa jauh kemampuan model dalam menerangkan variasi variabel dependen. Nilai koefisien determinasi adalah antara nol dan satu (Ghozali, 2006). Nilai koefisien determinasi dapat dilihat pada tabel 5.7 di atas.

Hasil perhitungan dengan menggunakan program SPSS versi 16 dapat diketahui bahwa koefisien determinasi yang diperoleh sebesar 0,888 . Hal ini berarti $88,8 \%$ loyalitas nasabah dapat dijelaskan oleh variabel citra merek, sedangkan sisanya yaitu $11,2 \%$ kepuasan pelanggan dipengaruhi oleh variabel-variabel lainnya yang tidak diteliti dalam penelitian ini.

\section{KESIMPULAN DAN SARAN}

\section{Kesimpulan}

Berdasarkan hasil penelitian dan pembahasan, maka dapat ditarik kesimpulan sebagai berikut:

1. Citra merek yang terdiri dari citra perusahaan, citra konsumen, dan citra produk, berpengaruh signifikan terhadap loyalitas nasabah pada PT. Bank Rakyat Indonesia Tbk Unit Bumi Nyiur Kantor Wilayah Kota Palu.

2. Citra perusahaan berpengaruh signifikan terhadap loyalitas nasabah pada PT. Bank Rakyat Indonesia Tbk Unit Bumi Nyiur Kantor Wilayah Kota Palu.

3. Citra kosumen berpengaruh signifikan terhadap loyalitas nasabah pada PT. Bank Rakyat Indonesia Tbk Unit Bumi Nyiur Kantor Wilayah Kota Palu.

4. Citra produk berpengaruh signifikan terhadap loyalitas nasabah pada PT. Bank Rakyat Indonesia Tbk Unit Bumi Nyiur Kantor Wilayah Kota Palu.

\section{Saran}

Berdasarkan hasil penelitian, pembahasan dan kesimpulan yang diperoleh, maka saran yang dapat diberikan sebagai berikut:

\section{Bagi Perusahaan}

(1) Hasil tanggapan responden mengenai indikator perusahaan terpercaya merupakan indikator dengan nilai mean terendah. Oleh karena itu, disarankan kepada PT. Bank Rakyat Indonesia Tbk Unit Bumi Nyiur Kantor Wilayah Kota Palu sebaiknya selalu menjaga kepercayaan perusahaan agar kepercayaan pelanggan dapat terjaga kepada perusahaan untuk dapat tetap menjadi pilihan bank terbaik yang dapat membuat pelanggan puas. Menjaga terpercayanya perusahaan dapat di mulai dengan memberikan nilai-nial positif bagi pelanggan seperti menangani dan memberikan solusi dengan cepat jika ada pelanggan yang menginginkan sesuatu dari perusahaan.

(2) Hasil tanggapan responden mengenai indikator status sosial merupakan indikator dengan nilai mean terendah. Oleh karena itu, Pihak manajemen PT. Bank Rakyat Indonesia Tbk Unit Bumi Nyiur harus perlu mengatur dan mengelola produk-produk yang ditawarkan sedemikian rupa lagi agar nasabah akan merasa berkelas jika menggunakan produk-produk yang ditawarkan oleh PT. Bank Rakyat Indonesia Tbk Unit Bumi Nyiur. 
(3) Hasil tanggapan responden mengenai indikator manfaat bagi konsumen merupakan indikator dengan nilai mean terendah. Oleh karena itu, disarankan kepada pihak PT. Bank Rakyat Indonesia Tbk Unit Bumi Nyiur untuk melakukan pengukuran kepuasan nasabah secara berkala 6 bulan sampai 1 tahun sekali sebagai bentuk pengukuran akan manfaat produkproduk yang ditawarkan kepada nasabah apakah sudah bermanfaat atau belum. Sehingga jika telah dilakukan pengukuran pemanfaatan produk ini akan memicu kepuasan nasabah dan dapat mendorong terciptanya loyalitas bagi nasabah.

(4) Hasil tanggapan responden mengenai indikator melakukan pembelian ulang merupakan indikator dengan nilai mean terendah. Oleh karena itu, agar supaya loyalitas pelanggan meningkat dan untuk mempertahankan yang selama ini sudah terlaksana dengan baik dibutuhkan tindakan langsung berupa kerja dari semua pihak termasuk karyawan maupun nasabah. misalnya nasabah memberikan masukan untuk perusahaan mengenai produk apa saja yang sesuai dengan kebutuhan nasabah sekarang.

2. Bagi Peneliti Selanjutnya

Bagi peneliti selanjutnya yang ingin meneliti atau melanjutkan penelitian ini, disarankan untuk meneruskan atau mengembangkan penelitian ini dengan mencari faktor lain yang dapat mempengaruhi loyalitas nasabah seperti faktor mutu produknya dan kualitas pelayanan.

\section{REFERENSI}

Anthony, Giddens. (2012). The Constitution of Society. Cetakan keempat. Yogyakarta: Pedati.

Ferrinadewi, Erna. (2008). Merek dan Psikologi Konsumen, Implikasi pada Strategi Pemasaran. Yogyakarta: Graha Ilmu.

Griffin, Jill, (2005). Customer Loyalty, Edisi Revisi. Jakarta: Erlangga.

Husein, Umar.(2013). Metode Penelitian untuk Skripsi dan Tesis. Jakarta: Rajawali. Husein, Umar (2010). Metode Riset Akuntansi Terapan. Jakarta: Gralia Indonesia Cetakan pertama. Kotler, Philip, dan Kevin Lane Keller. (2009). Manajemen Pemasaran, Jilid 2 Edisi Ketiga Belas. Jakarta: Penerbit Erlangga.

Kotler, P.dan Keller, K.L. (2012). Marketing Management (13th ed.). New Jersey: Prentice Hall, Inc. Roslina,(2010). Citra Merek: Dimensi Proses Serta Pengukurannya. Jurnal Bisnis Dan Manajemen, vol.6, no.3, hal.333-346.

Schiffman, L.G dan L.L Kanuk. (2013). Consumer Bahavior. $7^{\text {th }}$ Edition. New Jersey: Prentice Hall. Sangadji, Etta Mamang dan Sopiah. (2013). Perilaku Konsumen. Yogyakarta: Cv.Andi Offset.

Sugiyono, (2014). Metode Penelitian Bisnis (Pendekatan. Kuantitatif, Kualitatif, dan R\&D), Cetakan Ke-18. Bandung: Alfabeta.

Tjiptono, Fandy. (2008). Strategi Pemasaran. Yogyakarta: Penerbit Andi.

Tjiptono, Fandy, (2011). Pemasaran Jasa. Malang: Bayumedia. 